\title{
HIGH TEMPERATURE SURFACE MEASUREMENTS USING LIFETIME IMAGING OF THERMOGRAPHIC PHOSPHORS: BONDING TESTS
}

\author{
S. W. Allison, D. L. Beshears, Thomas Gadfort \\ Oak Ridge National Laboratory \\ Oak Ridge, Tennessee \\ T. Bencic, J. Eldridge \\ NASA Glenn Research Center \\ Cleveland, Ohio \\ W. A. Hollerman and P. Boudreaux \\ University of Louisiana - Lafayette \\ Lafayette, Louisiana
}

\begin{abstract}
Temperature-sensitive paint (TSP) comprised of thermally sensitive phosphor can provide a viable means for noncontact thermometry in wind tunnel and other aeropropulsion applications. Described here are recent results aimed at developing a phosphor and binder system that will cover a wide temperature range, ambient to $1000 \mathrm{C}$. The phosphor/binder mixture is to be sprayed directly on the surface with an airbrush. Whereas many surfaces are candidates for various uses, the present effort concerned silicon carbide, silicon nitride and silica substrates. Initial tests show that a phosphor mixture with two water-soluble materials, designated LK and HPC and manufactured by ZYP Inc., adhered well to these substrates. This same material was earlier shown to function well on a high strength nickel alloy. ${ }^{1}$
\end{abstract}

\section{INTRODUCTION AND BACKGROUND}

Phosphor coatings are the basis for a viable means of measuring temperature in a wide variety of situations. A phosphor is a fine powder that efficiently fluoresces when suitably excited by sources such as lasers, light-emitting diodes, ultraviolet lamps, or electron beams. A phosphor is thermographic when the

* This material is declared a work of the U.S. government and is not subject to copyright protection in the United States. fluorescence characteristics change with temperature. Fluorescence from a thermographic phosphor coating will indicate the temperature of the substrate to which it is attached, assuming, of course, that it is in thermal equilibrium. References 2 to 4 provide in-depth descriptions of the physical basis and many useful applications.

There are three main goals of the present effort. The first is to identify and test binders (also termed adhesives) that may be mixed with phosphors and coated onto surfaces of interest in a manner which results in a durable and uniform coating. The second is to identify and test phosphors or phosphor combinations that will indicate temperature between ambient and $1000 \mathrm{C}$. These phosphors must be suitable for fluorescent lifetime imaging. The third goal of the effort concerns layering different phosphor mixtures for heat flux and other diagnostic applications.

It may be noted that sputtering methods have been previously demonstrated to produce useful and durable coatings of phosphors. However, it is not always the case that the requisite equipment is available on a timely basis. It also places limitations on the size and shape of components that may be coated. Therefore, the present program concerns the development of phosphor/binder combinations that can be directly applied, such as by spraying or painting. 
$\underline{\text { Binders }}$

Reference 1 detailed several inorganic binders for initial tests on nickel alloy samples. The two top performing combinations were selected for testing on the non-metal substrates described here.

A 50/50 mixture of two materials, designated HPC and LK, produced by ZYP Coatings of Oak Ridge, TN. was recommended by the manufacturer. HPC is composed of magnesium and aluminum silicate. Maximum recommended temperature use is $1500 \mathrm{C}$. To cure, the material should be raised to $700 \mathrm{C}$ and brought back to room temperature slowly. It is a soft material thus it is mixed with LK. LK is silica-based with other additives. Maximum recommended temperature use is $1100 \mathrm{C}$ and it is cured the same as HPC.

Another material is Thinning Liquid \#14 which is manufactured by Sauereisen, Inc. of Pittsburgh, PA. It is commonly used for adjusting the viscosity of different types of cements. It is a soluble sodium silicate solution also used as a surface primer for heat-stable or chemical-resistant cements. The curing procedure consists of raising and holding to specific temperatures for an hour beginning just below $100 \mathrm{C}$ to $510 \mathrm{C}$. Further information regarding these materials can be found in reference 1 .

\section{Bonding Tests}

The goal of the bonding study is to demonstrate that phosphor mixed with the above binders will adhere and function to $1000 \mathrm{C}$. A sample preparation procedure and test matrix with results, Table 1, are given below. The sample evaluation consists of a visual inspection and fluorescence emission spectra for each sample as coated, after curing, and after each $1000 \mathrm{C}$ cycle. Emission spectra were taken using $260 \mathrm{~nm}$ excitation. The samples were elevated to $1000 \mathrm{C}$ at a ramp rate of $25 \mathrm{C} / \mathrm{min}$, held for one hour and then slowly cooled to room temperature in the oven. The loading condition is defined at the ratio of phosphor to binder by volume. It was $20 \%$ for all the tests. The phosphor was in all cases YAG:Eu. It is not expected that results should change with different phosphors. Eventually several different phosphors will be tested with selected binders.

\section{PREPARATION LIST}

1. Roughen and remove oil, etc. on sample surface with 150 grit sand paper.

2. Clean and remove all grit with Lacquer Thinner or acetone.

3. Elevate sample temperature to $1000 \mathrm{C}$ at a ramp rate of $25 \mathrm{C} / \mathrm{min}$ and hold for one hour.

4. Prepare binder phosphor mix with a single $20 \%$ loading by volume.

5. Heat sample surface to $150^{\circ} \mathrm{C}$ for the water-soluble binders LK/HPC mix and Sauereisen Thinning Liquid \#14.

6. Make sure the phosphor and binder are mixed well and apply a thin layer of phosphor to each sample.

7. Mark each sample.

8. Cure samples as required.

Prepare binder phosphor mix with a single $20 \%$ loading by volume.

Figure 1 is a photo of the test specimens after 5 cycles to $1000 \mathrm{C}$ for the HPC/LK combination. It is illuminated with an ultraviolet lamp which produces red fluorescence. Adherence in this case is judged by scraping a finger across the surface. The adherence and uniformity were good. The results were not so good for the Thinning Liquid \#14 binder. There was cracking and flaking. It may be that a change in sample preparation, loading condition, coating thickness, and/or curing schedule could improve upon this.

Reference 1 discussed several phosphors that are under consideration. These are $\mathrm{Y} 2 \mathrm{O} 3: \mathrm{Eu}$, YAG:Eu, YAG:Dy, YAG:Cr and YPO4:Dy. YAG:Eu was chosen for the present study since is has the most complex spectrum and might therefore be useful as a diagnostic since any chemical changes would likely produce a change in the spectrum. Figure 2 shows spectra from sample \#6, the CVD SiC material. It is seen that the spectra do not change with temperature cycling history. Therefore, the phosphor and binder are compatible. Figure 3 shows fluorescence from this sample on a sixth cycle to $1000 \mathrm{C}$ and the characteristic time response to short-pulse stimulation is seen. 


\section{CONCLUSIONS}

This program is in the early stages. Further effort will involve more tests of durability, cycling effects and phosphor calibration. Thus far, it appears that at least one coating, the $\mathrm{HPC} / \mathrm{LK}$ combination, will be useful for temperature sensing applications to $1000 \mathrm{C}$.

\section{REFERENCES}

1. Allison, S.W., Beshears, D.L., Bencic, T., Hollerman, W.A., and Boudreaux, P., July 9-11, 2001, "Development of TemperatureSensitive Paints for High Temperature Aeropropulsion Applications," Proceedings of the Joint Propulsion Conference of the AIAA, paper \# AIAA-2001-3528, Salt Lake City, Utah.

2. Noel, B.W., Turley, W.D., and Allison, S.W., 1994, "Thermographic Phosphor Temperature Measurements: Commercial and Defense-Related Applications," p. 271-288 in Proceedings of the 40th International Instrumentation Symposium, Instrument Society of America, Research Triangle Park, North Carolina.

3. Grattan, K.T.V., and Zhang, Z.Y., 1995, Fiber Optic Fluorescence

Thermometry, Chapman \& Hall, London.

4. Allison, S. W., and Gillies, G.T., , July 1997, "Remote thermometry with Thermographic Phosphors: Instrumentation and Applications," Rev. Sci. Instrum. 68(7), pp. 1-36.

This document was prepared by the Oak Ridge National Laboratory, Oak Ridge, Tennessee, managed by UT-BATTELLE, LLC, for the U.S. Department of Energy under contract DE-AC0500OR22725. Accordingly, the U.S. government retains a nonexclusive, royalty-free license to publish or reproduce these documents, or to allow others to do so, for U.S. government purposes. 


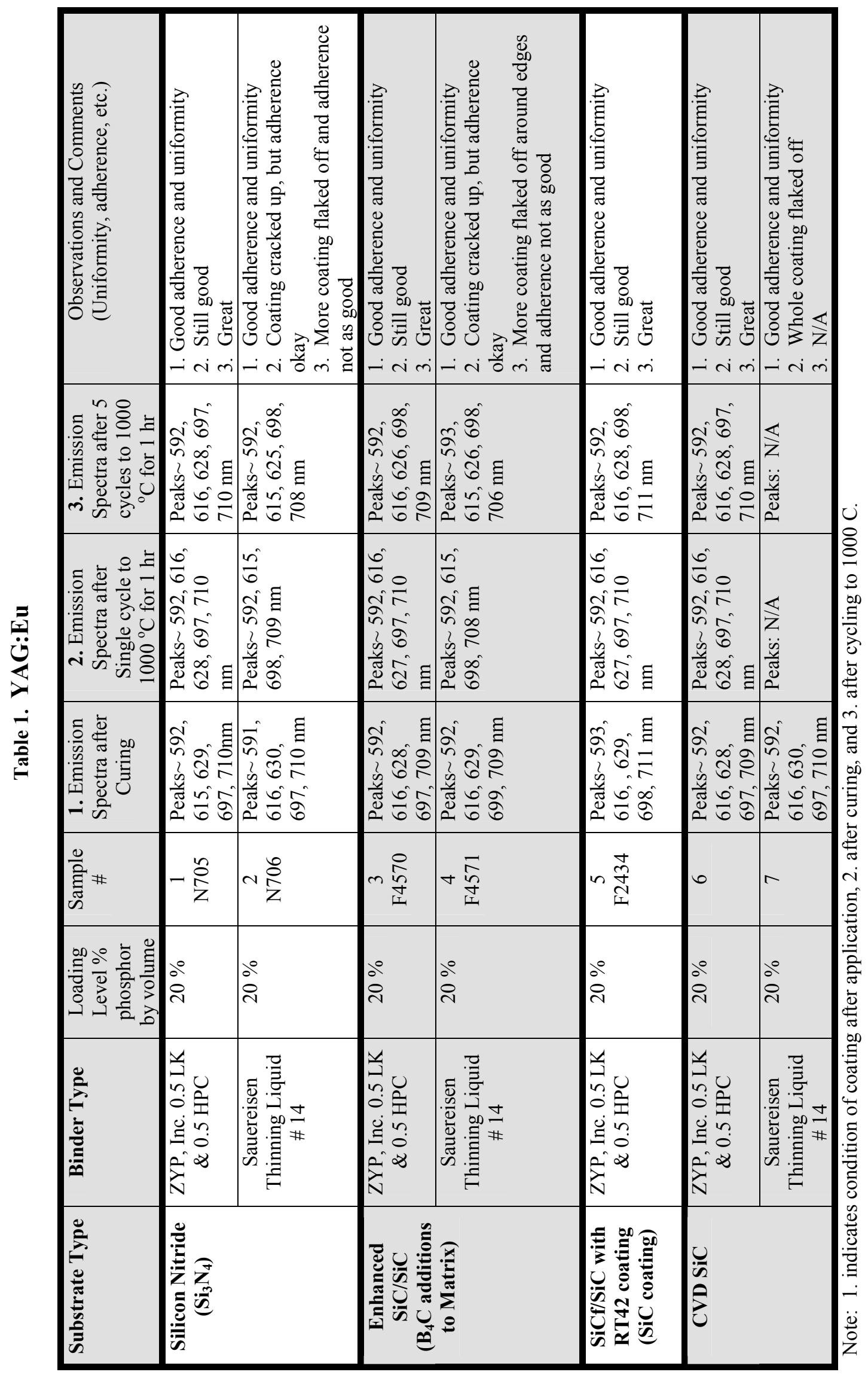




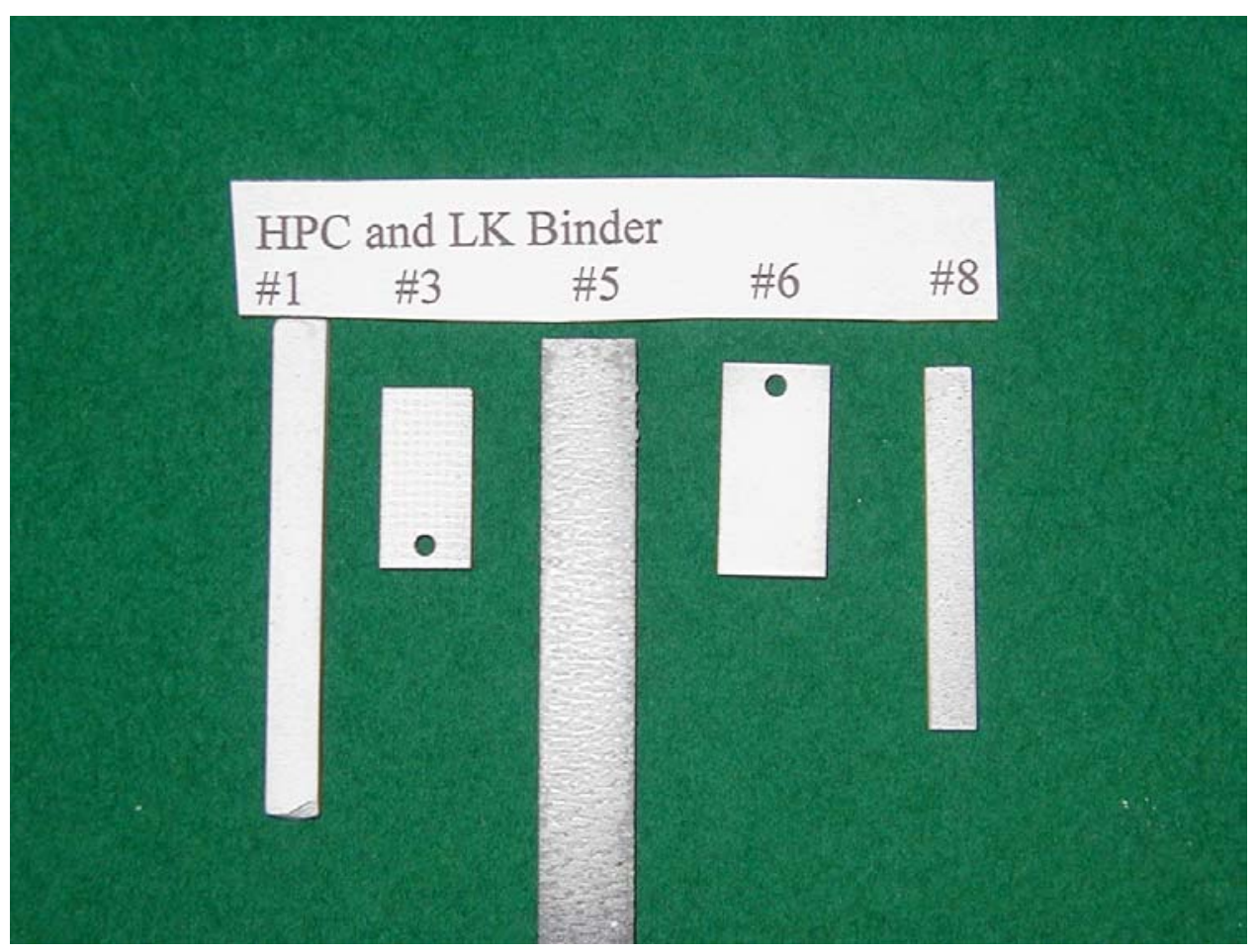

Figure 1. Photo of samples cycled five times to $1000 \mathrm{C}$.

\#6 YAG:Eu with HPC and LK binder

Substrate: CVD SiC Loading: $20 \%$ Phosphor

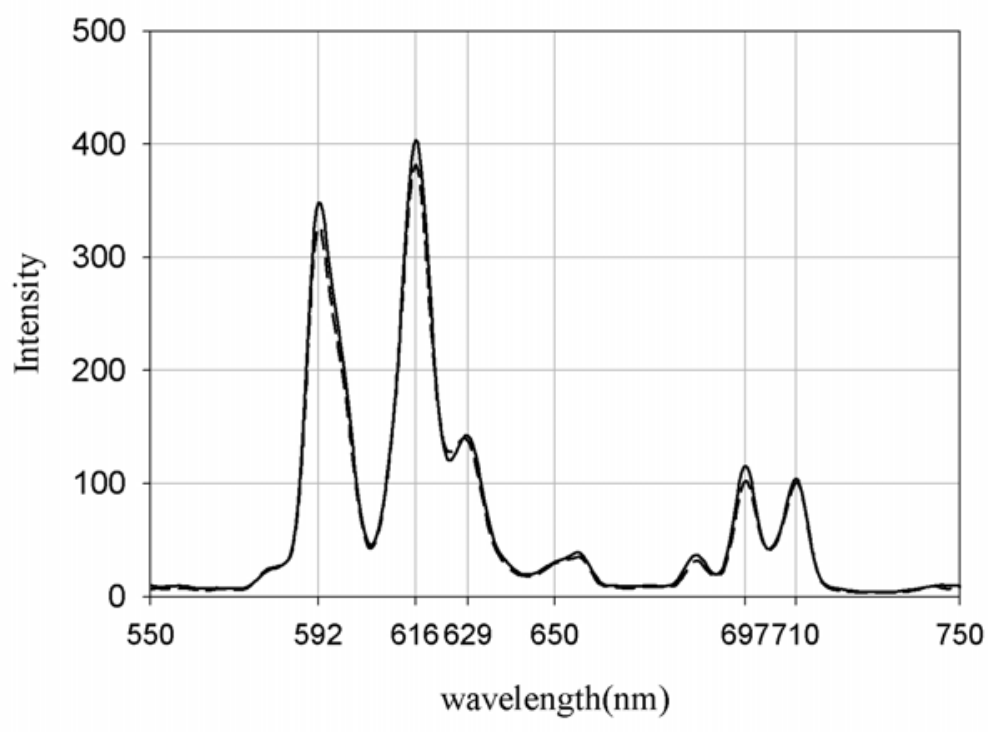

- wavelength(nm) vs int-after curing

- - wavelength(nm) vs int-after 5 cycles to $1000 \mathrm{C}$

Figure 2. Spectra of YAG:Eu phosphor mixed with HPC/LK binder. Excitation wavelength: $260 \mathrm{~nm}$. Exit slit: $15 \mathrm{~nm}$. Emission slit: $5 \mathrm{~nm}$. 


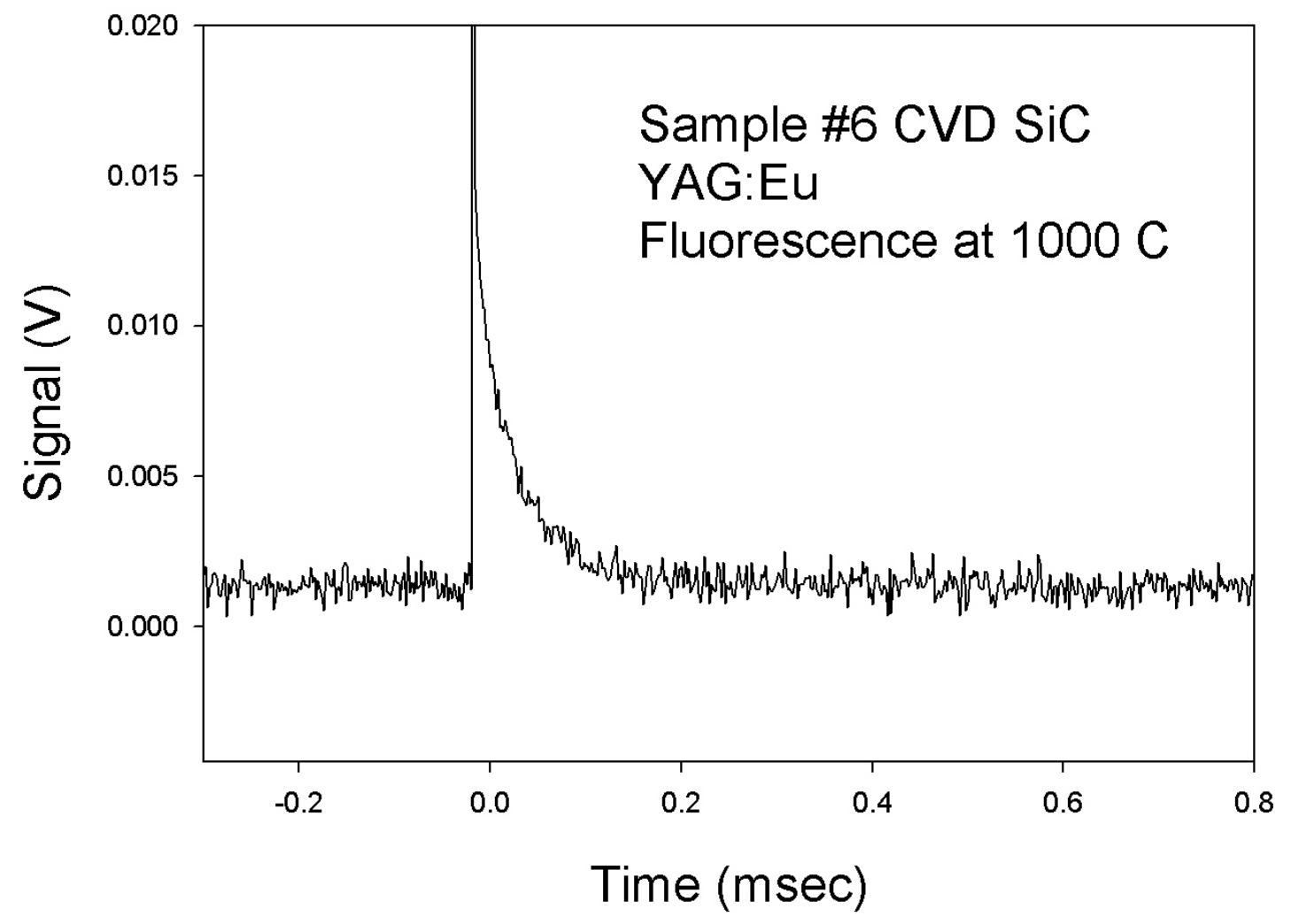

Figure 3. YAG:Eu fluorescence from sample 6, CVD SiC.

Excitation: 337 nm. Emission: 592 nm. 